
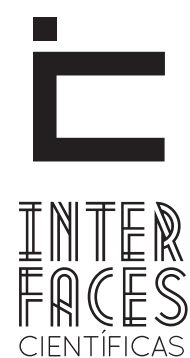

HUMANAS E SOCIAIS

\title{
MIGRAÇ̃ES INTERNACIONAIS E A DIÁSPORA CHINESA NO BRASIL
}

\section{RESUMO}

0 presente trabalho tem como objetivo principal apresentar um panorama geral das migrações internacionais para o Brasil, tendo como escopo a diáspora chinesa no país. A partir da leitura de autores que trabalham com as questões sobre migrações e do trabalho empírico realizado nas cidades de Aracaju e Salvador, construiu-se este artigo encarado como desafio diante das lacunas referentes ao estudo da presença chinesa no Brasil e em especial na região nordeste. A presença de imigrantes no Brasil foi bastante discutida no passado e conti- nua sendo discutida na contemporaneidade devido a existência de várias faces, tanto do ponto de vista econômico, quanto das relações sociais. Chineses ou não, a presença dos imigrantes constitui-se como promotora de novas sociabilidades a partir do encontro de diferentes culturas.

\section{PALAVRAS-CHAVE}

Migrações internacionais. Chineses. Diáspora. Nordeste. 


\section{ABSTRACT}

This paperaimsto provide an overviewof international migrationto Brazil, having asscopethe chinesediasporain the country. From the readingofauthors workingwith the issueson migrationandempirical work carried outin the cities ofSalvadorandAracaju, built thisarticleseen aschallenge beforethe gapsrelatedto the study of chinese presence inBrazilandespeciallyin the northeast. The presence ofimmigrantsinBrazilwasmuch discussedin the past andis still being discus-

\section{RESUMEN}

Este estudio tiene por objeto, proporcionar una visión general de la migración internacional en Brasil, y la diáspora china en el país. De la lectura de autores que trabajan con los temas de la migración y el trabajo empírico llevado a cabo en las ciudades de Salvador y Aracaju, se ha construido este artículo, teniendo como desafío los pocos registros existentes de la presencia de inmigrantes chinos en Brasil, en especial en la región Nordeste. La presencia de inmigrantes en Brasil, fue muy discutida en el pasado y todavía sedin contemporary timesdue tothe existence ofmany faces, both froman economic perspective, associal relations. Chineseor not, the presenceof immigrantswas established aspromoterofnew social arrangementsfrom themeeting of differentcultures.

\section{KEYWORDS}

International migration. Chinese. Diaspora. Northeast. sigue siéndolo, debido a la existencia de muchas facetas, tales como la económica, y las sociales. Chinos o no, la presencia de inmigrantes constituyese como promotora de nuevas relaciones sociales desde el encuentro de diferentes culturas.

\section{PALABRAS CLAVE}

Migración internacional. Chinos. Diáspora china. La inmigración. Nordeste. 


\section{INTRODUCÇÃO}

As migrações internacionais tiveram um importante papel no período em que os Estados Nacionais se consolidaram. Destacam-se os Estados Unidos, Argentina e o Brasil, países que receberam um grande quantitativo de imigrantes que aportaram e constituíram o que hoje são esses países. Fugidos da falta de emprego e alimentos, atraídos pelas propostas de trabalho e meios de ascensão econômica e social, os imigrantes foram chegando à América aos milhares num grande movimento que encontrou o seu auge no fim do século XIX (KLEIN, 2000). Vieram "fazer a América” e buscar novas oportunidades.

0 presente trabalho tem como objetivo principal apresentar um panorama geral das migrações internacionais para o Brasil, tendo como escopo a diáspo$\mathrm{ra}^{2}$ chinesa no país. Construiu-se este artigo a partir da leitura de autores que trabalham com as questões sobre imigração, como Martins (1973), Silva (2006; 2008), M. Silva (2008) e outros, além do trabalho empírico realizado nas cidades de Aracaju e Salvador. 0 trabalho de campo foi realizado nos anos de 2012 e 2013 a partir de fontes documentais (jornais), de entrevistas semipadronizadas e da observação direta. 0 início da pesquisa se deu na cidade de Salvador, todavia, a cidade de Aracaju prevaleceu como recorte empírico devido a dimensão que o trabalho tomaria e as dificuldades impostas à pesquisa no decorrer de sua realização.

Tendo em vista o caráter bibliográfico deste trabalho, os apontamentos sobre o trabalho de campo serão introduzidos de maneira secundária no último ponto deste artigo.

Nenhum estudo pretende abarcar todos os fluxos migratórios, de todos os grupos e em todas as épocas. Assim, coloca-se que o que está apresentado nes-

2. 0 termo diáspora, empregado neste artigo, está relacionado à dispersão e deslocamento de determinado grupo. Para mais detalhes sobre estudos de diásporas ver Hall (2008). te trabalho é apenas parte de algumas experiências migratórias ocorridas a partir da segunda metade do século XIX, dentre as quais, a diáspora chinesa em algumas regiões do país.

No primeiro tópico discutir-se-á acerca do período das imigrações em massa para o Brasil no século XIX e início do século XX e os fluxos migratórios contemporâneos para o Brasil. No segundo ponto apresentar-se-á parte da experiência da diáspora chinesa, tendo como alvo as migrações atuais. No terceiro ponto discorrer-se-á a migração chinesa para a região nordeste brasileira, no qual, serão apresentados alguns resultados do trabalho empírico realizado.

A presença de imigrantes no Brasil foi bastante discutida no passado e continua sendo discutida na contemporaneidade, devido a existência de várias faces, tanto do ponto de vista econômico quanto das relações sociais. Chineses ou não, a presença dos imigrantes constitui-se como promotora de novas sociabilidades a partir do encontro de diferentes culturas.

\section{BRASIL DOS IMIGRANTES: PASSADOEPRESENTE DOSFLUXOS MIGRATÓRIOS PARA OBRASIL}

Os fluxos migratórios tiveram um papel fundamental na consolidação dos Estados nacionais. Na Europa, houve a participação dos imigrantes na consolidação de Estados nacionais e de suas economias, como foi o caso da Alemanha e da França antes da Segunda Guerra Mundial (CASTLES; MILLER, 2004, p. 70).

Tema muito explorado nos debates sobre o suprimento de mão de obra, a vinda dos imigrantes para o Brasil não foi consensual, enfrentou resistência, contudo, propiciou um conjunto de elementos que serviram de base para o aparecimento de diversas modificações na estrutura social e econômica do 
país. A chegada dos imigrantes não foi bem aceita por todos e os debates do Parlamento da época mostram que as propostas para a imigração divergiam em muitos aspectos.

Para Martins (1973) o que suscitou a vinda do braço imigrante foi uma crise agrária instalada no país desde a publicação da Lei de Terras em 1850, que privava o Brasil de ter uma classe de pequenos proprietários. Esta lei era um prelúdio do que viria acontecer anos mais tarde: a abolição do regime escravista que liberava a mão de obra escrava para se tornar assalariada ou proprietária. Todavia, como a terra agora só poderia ser adquirida por meio da compra, os ex-escravos ou continuaram nas fazendas ou foram desenvolver cultivos em terras "sem dono".

Depois de várias discussões no Parlamento da época, venceu a posição dos parlamentares e senhores de terra do sudeste e vigorou-se a subvenção à imigração para suprir a necessidade de mão de obra de suas lavouras ${ }^{3}$. Todavia, o trabalhador imigrante deveria ter aptidão para a agricultura e ser pouco exigente com relação às condições de trabalho, além disso, havia uma preocupação com o branqueamento do Brasil, em que, o imigrante branco e europeu era o portador da civilidade que faltava a outros povos. Assim, vários grupos chegaram ao Brasil com o objetivo e o sonho de mudar de vida e fugir da situação econômica precária pela qual passou a Europa em muitos momentos. Eram alemães, espanhóis, italianos, portugueses que aportavam nos portos e encaminhados diretamente aos seus empregadores, ávidos por suprir suas necessidades (MARTINS, 1973).

Os espanhóis, italianos e portugueses representaram o maior número de imigrantes no fim do século XIX, contudo, vê-se a intensificação da entrada de grupos não-europeus a partir do afrouxamento das questões relacionados à política de branqueamento e a própria legislação que impedia a entrada de outras

3. Sobre os debates no Parlamento Brasileiro acerca da imigração no século XIX, consular Lazzari (1980). nacionalidades. Os japoneses foram os mais numerosos (mais de 110 mil no período entre 1924 e 1933), chegaram em 1908 e ao longo do século XX, também, serviram aos propósitos das lavouras do sudeste no princípio (IBGE, 2000, p. 226), como aponta Sakurai:

A imigração japonesa para o Brasil se inicia em 1908 quando os primeiros 781 imigrantes chegaram ao porto de Santos. Daquele ano em diante, 234 mil imigrantes se fixaram em todas as partes do País, mas sobretudo nos estados de São Paulo e Paraná. No início da década de 1990 somavam, com seus descendentes, cerca de 1,2 milhões de pessoas. (SAKURAI, 2000, p. 201).

Muito se diz sobre a importância da imigração no contexto do processo de urbanização do estado de São Paulo e na formação de uma classe dirigente imigrante (BRESSER-PEREIRA, 1973). Também, no que diz respeito à continuidade dos fluxos migratórios para o Brasil no decorrer do século passado, já finalizado aquele período da subvenção, é preciso colocar em evidência que a relação com os fluxos do passado deram suporte a continuidade desses fluxos. Assim, as redes estabelecidas com aqueles que já estavam aqui e constituíram seus patrimônios foram fundamentais para que a vinda de imigrantes prosseguisse; alguns casos mais forte do que outros. Os sírios e libaneses e os armênios, por exemplo, estabeleceram importantes redes de solidariedade migratórias na capital paulista. Aqueles que já estavam aqui forneciam capital e informações para o estabelecimento e inserção dos que chegavam (TRUZZI, 2009; GRÜN, 1992).

Mas, a imigração estrangeira não se restringiu apenas às regiões sul e sudeste, outras regiões receberam fluxos migratórios, porém, em proporção muito menor. A Bahia recebeu um importante contingente de espanhóis na segunda metade do século XIX, principalmente de origem galega (BARCELAR, 1992). Já no século $X X$, algumas tentativas de implantação de núcleos coloniais, também, ocorreram, como no caso das colônias japonesas de Una (sul da Bahia) e JK (próxima a Salvador), ambas ainda possuem japoneses e seus descendentes vivendo na região. 
Algumas tentativas não foram tão exitosas, como foi o caso de Sergipe. No fim do século XIX, seguindo a tendência do sudeste brasileiro, os deputados do Parlamento sergipano discutiram e aprovaram a subvenção e a inserção de mão de obra imigrante na lavoura sergipana com o propósito de criar uma colônia imigrante no município de São Cristóvão (PASSOS SUBRINHO, 2000). Inicialmente o grupo selecionado foi o de “chins", provavelmente, asiáticos, contudo, a vinda dos imigrantes só foi concretizada nos anos de 1920, sendo que, o grupo que aportou em terras sergipanas foi o de alemães e sem cumprir o objetivo principal.

\begin{abstract}
A colônia não prosperou e as causas mais específicas para que isto tenha ocorrido ainda não estão claras. A história da imigração demonstra que em outras regiões do Brasil as experiências bem sucedidas não excluíram outras que não prosperaram. Deste modo, parece ser adequado dizer que o "fracasso" da colônia de Quissamã não está associado a fatores que não estivessem presentes em outros estados e que, possivelmente, o que faltou foram novas iniciativas. (ENNES; GOES; NETO, 2012, p. 154).
\end{abstract}

Não demorou muito e a colônia de imigrantes alemães se dissipou. 0 abandono da incipiente colônia pode ter ocorrido pelas mortes causadas por doenças tropicais não conhecidas por eles e pelas precárias condições de trabalho. (FELTE BEZERRA, 1984).

Atualmente, o Brasil tem recebido grandes contingentes de imigrantes de algumas nacionalidades que não se inseriram no período da migração em massa para o Brasil. Alguns grupos são mais numerosos que outros, mas todos chegam com expectativas de ganhar dinheiro e ajudar seus parentes que ficaram no país de origem. Os bolivianos e peruanos são mais numerosos e é evidente que as estatísticas oficiais não conseguem captar o montante de imigrantes, vivendo de forma irregular.

Grande parte dos bolivianos chega a São Paulo por meio de agenciadores que anunciam as ofertas de trabatho nas cidades bolivianas que já têm histórico de emigração. Os imigrantes bolivianos que chegam, também, têm conhecidos ou parentes trabalhando nas oficinas têxteis da capital e região metropolitana, o que precisa ser levado em consideração, trata-se de uma rede migratória bastante consolidada (SILVA, 2006; 2008).

Ainda pouco estudada, a imigração peruana para - Brasil, em particular para São Paulo, possui características semelhantes à imigração boliviana. Eles já ultrapassaram o número de 30 mil pessoas em 2007 e se concentram em sua maioria na capital paulista (FÁVARI, 2011).

Distanciando-se de São Paulo tem-se uma pequena, mas crescente comunidade árabe (palestinos, sírios, libaneses e jordanianos) em Santa Catarina (mais precisamente em Florianópolis). Muitos destes imigrantes de língua árabe fazem parte do contingente de refugiados que são abrigados pelo Estado brasileiro por meio das convenções internacionais, todavia, já se sabe que uma rede migratória está estabelecida e muitos já estão inseridos no campo econômico de maneira significativa, constituindo uma comunidade imbuída de mecanismos de ajuda mútua (CAMPOS, 2011).

Novos movimentos migratórios têm sido observados e outros têm se intensificado. As últimas crises econômicas mundiais estão permitindo o aparecimento de novos fluxos, principalmente entre Europa e América Latina. São portugueses, espanhóis, franceses e alemães que, diante da falta de emprego, tem migrado para os países latino-americanos, dentre os quais o Brasil que ocupa uma posição de destaque (DN, 2011; GIRALDI, 2012). Mas, outros grupos, também, têm aportado no Brasil por questões humanitárias, tais como os haitianos e sírios refugiados da fome e da guerra. (ANSA, 2012; ESTADO DE SÃO PAULO, 2013)

\section{A CHINA NO BRASIL: APONTAMENTOS SOBRE A IMIGRAÇÃO CHINESA NO BRASIL}

A presença de chineses remonta ao século XIX, mais precisamente o ano de 1810 quando que por 
determinação de D. João VI alguns chineses foram trazidos para desenvolver o cultivo de chá onde hoje é o Jardim Botânico. As semelhanças com o clima, a possibilidade de ganhos com o cultivo e o fato de Portugal possuir uma colônia em território chinês foram os fatores que propiciaram esse recrutamento de mão de obra que logo foi frustrada pelo tratamento severo que era dispensado aos trabalhadores, resultando numa fuga em massa dos chineses para as cidades e, obrigando-os a se registrarem com nomes brasileiros. É por volta de 1825 que os chineses começaram a desenvolver a atividade de mascateação, vendendo peixes e pastéis pelas ruas da capital do imperial (CHANG-SHENG, 2009; LIMA, 2008).

Sucessivos debates sobre a introdução da mão de obra chinesa foram travados no decorrer do século XIX e início do século XX, ora imigrantes chineses chegavam, ora eram proibidos esses recrutamentos por meio de acordos, conforme aponta Lesser:

À medida que outros impérios cresciam à custa de mão-de-obra "coolie", surgiu uma discussão sobre trabalho/ cultura, tratando da possibilidade de os trabalhadores chineses virem a enriquecer economicamente o Brasil ou se, ao contrário, eles prejudicariam sua cultura, transformando-a de "européia" em "asiática". A entrada dos chineses nunca pôde ser desvinculada das ideias sobre o futuro do Brasil. (LESSER, 2001, p. 38)

A discussão sobre a imigração asiática e chinesa tornara-se parte da discussão sobre a formação do Brasil e do povo brasileiro. Havia parlamentares contra e a favor da introdução de mão de obra chinesa, como também, instituições com posições contrárias, mas todos dominados pelo receio do elemento "amarelo" e se ele seria suficiente para modernizar o país.

É importante observar que a imigração chinesa para o Brasil tem um histórico e viveu outras fases, mas, é sobretudo, na contemporaneidade que se demarca a discussão sobre a presença chinesa no Brasil, onde, apesar de possuir o maior contingente de imi- grantes chineses na América Latina, os estudos ainda são pouco expressivos em termos quantitativos.

O estado de São Paulo, o maior receptor de imigrantes, ainda é o preferido por parte dos chineses na atualidade, embora outros estados e cidades brasileiras tenham surgido como opções num mundo cada vez mais globalizado. A capital paulista concentra $90 \%$ de toda a população chinesa do país, estimada em 200 mil pessoas, entre imigrantes e descendentes (VÉRAS, 2008, p. 128). 0 alto número de indocumentados e a adoção de outras nacionalidades no processo migratório são fatores que dificultam uma estimativa mais precisa (VÉRAS, 2008, p. 129).

Em São Paulo, novos e antigos imigrantes chineses se reúnem em alguns espaços de sociabilidade. O Centro Social Chinês do Brasil, a Missão Católica Chinesa, a Igreja Cristã Chinesa no Brasil e vários templos budistas são exemplos da dimensão e da diversidade que a colônia chinesa em São Paulo possui.

Bairros como Centro, Bom Retiro, Aclimação, Pinheiros e Liberdade seguem tradicionais na recepção destes chineses em busca de oportunidades de negócios e trabalho. Embora os imigrantes chineses venham intermediados por seus compatriotas com propostas de emprego, muitas vezes com pouca qualificação, já se é possível observar muitos importadores e atacadistas chineses atuando na cidade, fornecendo e distribuindo produtos chineses para todo o país e quiçá para a América do Sul. Aqueles que vão à China fazer negócios nos anos atuais, também, indicam a capital paulista como sendo um centro de oportunidades (ESTADO DE SÃO PAULO, 2012).

Contudo, o Rio de Janeiro figura ao lado da capital paulista como um reduto chinês de longa data, dessa maneira, é preciso citar alguns aspectos desta presença na atualidade. A maioria dos chineses se estabeleceu na região do Saara, bairro que tem sua origem na grande quantidade de comerciantes árabes que vendiam produtos provenientes do Oriente Médio, 
onde se sobrepuseram aos árabes, judeus, coreanos e japoneses. Já em 2007 a quantidade de lojas chegou a 40 ou um total de $20 \%$ "do espaço comercial da área" (ARAÚJO, 2010).

No Rio de Janeiro os chineses se reúnem em torno de duas associações, uma ligada ao governo de Pequim (Associação Chinesa do Rio de Janeiro) e a outra ao governo de Taiwan (Centro Social Chinês do Rio de Janeiro). Apesar da rivalidade entre os governos, as divergências são diminuídas pelo sentimento de solidariedade e ajuda mútua que povoa os grupos chineses fora da China (CHANG-SHENG, 2009, p. 8).

O estado do Paraná, também, possui uma presença chinesa significativa. 0 início desse movimento se deu na década de 1920 com alguns chineses que aportaram, porém, somente a partir da década de 1980 o fluxo é intensificado com a chegada de 200 famílias vindas de Moçambique (CHEN, 2010). Nos anos 1990 muitos chineses da China Continental, Hong Kong e Taiwan vieram para trabalhar no ramo do comércio. Atualmente, Curitiba possui cerca de 3 mil chineses que frequentam a Associação Cultural Chinesa do Paraná, a Igreja Presbiteriana Chinesa e o Clube Santa Mônica, este último, embora não tenha sido fundado por chineses têm um considerável número de sócios desta nacionalidade (CHEN, 2010).

No próximo ponto, serão apresentadas algumas colocações sobre a imigração chinesa recente na região nordeste do Brasil. A região é vista como rota alternativa aos grandes centros urbanos do sudeste, onde, alguns imigrantes têm visto como lugares saturados para os negócios. É fato que o nordeste tem despontado como uma região que tem atraído grandes investimentos e apresentado taxas de crescimento acima da média nacional. Esses fatores levam não só a migração de investimentos, como também, de chineses que querem obter mais ganhos do que aqueles obtidos nas grandes aglomerações urbanas.

\section{IMIGRAÇÃO CHINESA NO NORDESTE BRASILEIRO}

Tratar a imigração chinesa na região nordeste, no último ponto deste trabalho, apresenta-se como um desafio diante das escassas publicações disponíveis para consulta. $O$ fato de o nordeste se inserir no quadro geral de crescimento econômico do Brasil coloca a região na rota das migrações internacionais, restritas antes às regiões sul e sudeste. Isto tem relação com um fenômeno mais amplo: a mobilidade do capital que permite a migração de postos de trabalho, investimentos e consequentemente das pessoas.

Assim, vê-se uma migração mundial norte-sul e sul-sul mais diversificada e, dentro do Brasil outras regiões, também, absorvem parte desses novos imigrantes. É claro que a região sudeste e o estado de São Paulo não deixaram o seu protagonismo, como no caso da imigração boliviana, peruana e até chinesa, mas se quer chamar a atenção para o fato de que o nordeste tem sido preferido por imigrantes chineses que pretendem aproveitar essa expansão econômica.

Em Pernambuco os chineses e os seus descendentes já contabilizam algo em torno de duas mil pessoas (entre legais e ilegais) segundo estatísticas informais (SILVA, M., 2008). Concentram-se, sobretudo, em Recife e Caruaru, onde as possibilidades econômicas são maiores e o número de compatriotas também (SILVA, M., 2008).

Semelhante a outros lugares, em Pernambuco eles se inserem no campo econômico a partir das redes étnicas que promovem a ajuda mútua com o objetivo de viabilizar o êxito econômico. Como encontrou M. Silva (2008), a experiência como assalariados nos negócios de parentes e amigos foi utilizada como alavanca para a abertura do seu próprio negócio e a possibilidade de ascensão econômica e social.

Na Bahia, assim como Pernambuco, a imigração chinesa está um pouco mais consolidada do que nos outros estados. No trabalho de campo realizado na ci- 
dade de Salvador (janeiro/2012) encontra-se a Associação Chinesa da Bahia, promovendo comemorações e eventos de "integração com a sociedade baiana". Havia, também, imigrantes chineses de segunda geração, ocupando cargos importantes de assessoria de imprensa política, além daqueles que possuem negócios diferentes dos quais os chineses de primeira geração estão inseridos e continuam a se inserir: venda de produtos importados, restaurantes e pastelarias. Em Feira de Santana, por exemplo, a maior feira do centro da cidade tem o nome de "Feiraguai" por causa da antiga origem dos produtos, antes vinham do Paraguai, hoje vem diretamente da China, cujos imigrantes dominam o mercado local desse tipo de mercadoria (FOLHA DE SÃO PAULO, 2011).

Essa presença, ainda que tímida, em relação às estatísticas expressivas da região sudeste, principalmente em São Paulo, tem recebido atenção da imprensa local e nacional e dos comerciantes e empresários locais. Muitos se dizem assustados, outros se mostram receptivos devido aos vultosos investimentos chineses, como é o caso de um dos diretores da Associação Comercial da Bahia, mostrado por meio do trabalho de campo.

Em Aracaju, realizou-se um trabalho empírico nos anos de 2012 e 2013 , onde se pode observar que os chineses se concentram na região de comércio popular, o centro da cidade. Segundo estatísticas da Polícia Federal, no ano de 2012 havia 63 chineses registrados, contudo, nem sempre é possível mensurar a totalidade dos imigrantes, visto que, algumas situações interferem na contabilização e localização deles, por exemplo, a imigração ilegal ou falta de registro.

$\mathrm{Na}$ capital sergipana é possível encontrar dois tipos de inserção destes imigrantes: as lojas de produtos importados e os restaurantes e pastelarias. A partir desta inserção depreendem-se dois pontos. 0 primeiro é a popularização dos estabelecimentos do setor alimentício (restaurantes e pastelarias) que são muito frequentados pelos brasileiros.
O segundo ponto é a mudança no campo econômico, particularmente no subcampo do comércio de produtos importados. A inserção da China no circuito global de produção de mercadorias contribuiu para que alguns desses chineses se tornassem fornecedores, ou atacadistas, como observado no trabalho de campo, dessas mercadorias para os brasileiros. Isto gerou um conflito dentro do campo econômico, identificado nas entrevistas feitas com os comerciantes brasileiros. Muitos levantaram a hipótese da sonegação de impostos, da facilitação para instalação dos negócios pelas autoridades governamentais, da intermediação de outros chineses que estão na China, como mostra o trecho abaixo

\begin{abstract}
Esses imigrantes chineses compram as mercadorias em grandes quantidades (contêineres) e com ajuda da burocracia a favor deles, da corrupção, é que eles conseguem comprar toda essa mercadoria da China, fazendo com que a concorrência seja desleal. E, a culpa é sempre do poder público, somos irresponsáveis por que permitimos a entrada dessas pessoas. (Maria, brasileira e gerente de uma loja de produtos importados).
\end{abstract}

É interessante apontar que em Aracaju encontram-se dois processos migratórios, o de imigração e o de reimigração. No primeiro, os chineses chegaram à cidade vindos diretamente da China, já no segundo, os imigrantes vieram de outros estados ou países. Nos dois casos, a viagem, o estabelecimento e o sucesso econômico, estão diretamente ligados a existência de redes de ajuda mútua construídas entre os que estão aqui e os que têm a pretensão de vir.

Por fim, cabe acrescentar que ser chinês em Aracaju não tem somente um sentido. É uma construção que envolve vários fatores, entre eles a autonomeação e a heteronomeação. Eles dizem o que são e os outros, neste caso os brasileiros, dizem o que eles são, num jogo de relações de poder no qual prevalece a nomeação de quem está mais bem posicionado no campo de forças.

Diante disto, é possível dizer que o nordeste faz parte do novo quadro na migração mundial que se 
projeta no Brasil, intensificando os deslocamentos, diversificando os fluxos, muito embora em número menor como ocorreu no país nos séculos XIX e XX. Sua expansão econômica, o aumento dos rendimentos dos nordestinos, os investimentos chineses na região, a chamada "saturação" e a alta concorrência na região sudeste tem redirecionado antigos e novos imigrantes para as terras nordestinas em busca do êxito econômico e de um espaço sob o sol do nordeste.

\section{CONSIDERAÇ̃̃ES FINAIS}

Este trabalho nasceu a partir da necessidade de traçar um panorama sobre as migrações internacionais, sobretudo, sobre a diáspora chinesa no Brasil. A partir da leitura de diversos autores, dentro das duas correntes que estudam imigração e das incursões a campo, foi possível desenvolver este breve trabalho que está inserido dentro da dissertação de mestrado desta pesquisadora.

Pode-se concluir que as migrações para Brasil foram importantes do ponto de vista econômico e social, mas que não ocorreram de forma consensual, pois, travaram-se intensos debates sobre a melhor forma de se introduzir a mão de obra imigrante. É fato que a posição prevalecente foi à subvenção ou financiamento da imigração para suprir a necessidade da falta de trabalhadores, resultado da libertação dos escravos.

Na contemporaneidade, muitos fluxos do passado alimentam o presente, todavia, novos grupos têm se inserido no atual contexto das imigrações para o Brasil, tais como, peruanos, bolivianos, chineses, além de haitianos e palestinos fugidos dos conflitos armados e da escassez material.

A diáspora chinesa não é um fenômeno novo, sobretudo nos Estados Unidos e na Europa, onde grandes quantidades de imigrantes chineses constituíram o que conhecemos como chinatowns. 0
Brasil se constitui como rota para os chineses que procuram aproveitar as oportunidades econômicas ampliadas a partir da inserção da China no circuito da economia global.

Por fim, o nordeste brasileiro apresenta-se como rota primária e secundária para os novos chineses. É uma rota primária porque aqueles que já estão estabelecidos viabilizam a vindo de outros chineses que estão na China ou em outros países. Aparece como rota secundária, pois, alguns deles saem de outras regiões brasileiras e emigram na busca pelo êxito econômico.

\section{REFERÊNCIAS}

ANSA. Imigração haitiana é a maior desde a chegada de japoneses e italianos. 12 janeiro 2012.Disponível em: <http://noticias.r7.com/brasil/noticias/imigracaohaitiana-e-a-maior-desde-a-chegada-de-japoneses-eitalianos-20120112.html Imigração haitiana é a maior desde a chegada de japoneses e italianos>. Acesso em: 15 fev. 2012

ARAÚJO, M. S. Chineses no Rio de Janeiro: notas sobre nação, Chineses no Rio de Janeiro: notas sobre nação, território e identidade através da prática comercial e religiosa. Cadernos do CEOM, Chapecó, n.32, p.221240, 2010. Disponível em: <http://apps.unochapeco. edu.br/revistas/index.php/rcc/issue/view/77>. Acesso em: 17 fev. 2014

BACELAR, J. A. A presença espanhola na Bahia: os galegos no paraíso racial (1900-1950). Salvador: Centro Editorial e Didático da Universidade Federal da Bahia, 1992.

BEZERRA, F. Etnias sergipanas: contribuição ao seu estudo. Aracaju: J. Andrade, 1984.

BRESSER-PEREIRA, L. C. Origens étnicas dos dirigentes das empresas paulistas. RAE, São Paulo, n.13, 1973. 
CAMPOS, E. C. Estrangeiros numa Itha: Comunidade Árabe Islâmica em Florianópolis. In: XXVI SIMPÓSIO NACIONAL DE HISTÓRIA DA ANPUH, 2011, Anais... Disponivel em: <http://www.snh2011.anpuh. org/resources/anais/14/1300661060_ARQUIVO_ anpuh2011textofinalemersoncampos.pdf $>$. Acesso em: 4 maio 2012

CASTLES, Stephen; MILLER, Mark J. La era de la migración Movimientos internacionales de población en el mundo moderno. Colección América Latina y el Nuevo Orden Mundial. México: Miguel Ángel Porrua, UAZ, Cámara de Diputados LIX Legislatura, Fundación Colosio, Secretaría de Gobernación, Instituto Nacional de Migración, 2004.

CHANG-SHENG, S. Imigrantes e Imigração Chinesa no Rio de Janeiro (1910-1990). Revista Eletrônica Boletim do TEMPO, Rio de Janeiro, n.7, 2009. Disponível em: <http://www.tempopresente.org/index. php?option=com_content\&view $=$ article\&id $=4679$ : imi grantes-e-imigracao-chinesa-no-rio-de-janeiro-1910-1990\& catid=42\&ltemid=127>. Acesso em: 3 abr. 2012

CHEN, M. S. Cultura e educação dos imigrantes chineses na cidade de Cascavel: Dois mundos, um mesmo objetivo. 2010. Monografia (Especialização em História da Educação Brasileira). Centro de Educação, Comunicação e Arte, Universidade Estadual do Oeste do Paraná, Cascavel.

DN. Crise europeia relança imigração para América Latina. 30 de maio 2011. Disponível em: <http:// www.dn.pt/inicio/globo/interior.aspx?content_ $i d=1865149$ \&seccao=EUA\%20e\%20Am\%C3\%A9ricas $>$. Acesso em: 12 jan. 2012.

ENNES, M. A.; GOES, A. G. S.; NETO, E. A. Imigração no estado de Sergipe (1880-1930). Revista do Memorial do Poder Judiciário, Aracaju, n.2, p.133-156, 2013.

ESTADO DE SÃO PAULO. Brasil é a bola da vez para chinês imigrante. Disponível em: <www.estadao. com.br/noticias/cidades, brasil-e-a-bola-da-vez-para-chines-imigrante, $915147,0 . h t m>$. Acesso em: 20 nov. 2012.

ESTADO DE SÃO PAULO. São Paulo vive nova onda imigratória síria. 17 de fevereiro 2013. Disponível em: <http://noticias.uol.com.br/ultimas-noticias/agencia-estado/2013/02/17/sao-paulo-vive-nova-onda-imigratoria-siria.htm>. Acesso em: 14 mar. 2013.

FÁVARI, F. Migração Peruana em São Paulo: elementos comparativos com a imigração boliviana. In: XIX CONGRESSO INTERNO DE INICIAÇÃO CIENTÍFICA, 2011. Campinas. Resumos... Campinas: Universidade Estadual de Campinas, 2011. Disponível em: <http:// www.prp.unicamp.br/pibic/congressos/xixcongresso/ paineis/081415.pdf>. Acesso em: 17 out. 2012.

FOLHA DE SÃO PAULO. Pequenas Chinatowns se espalham pelo Nordeste. 24 nov. 2011 Disponível em: <http://www1.folha.uol.com.br/fsp/ cotidiano/16668-pequenas-chinatowns-se-espalham-pelo-nordeste.shtml>. Acesso em: 20 nov. 2012.

GIRALDI, R. Crise provoca êxodo de europeus para América Latina; Brasil é um dos países mais procurados. Disponível em: <http://www.ebc.com. $\mathrm{br} / 2012 / 10 /$ crise-provoca-exodo-de-europeus-para-america-latina-brasil-e-um-dos-paises-mais-procurados>. Acesso em: 11 jan. 2012.

GRÜN, R. Negócios \&famílias: armênios em São Paulo. São Paulo: Sumaré, 1992.

HALL, S. Da Diáspora: Identidades e mediações culturais. Belo Horizonte: UFMG, 2008.

IBGE. Brasil: 500 anos de povoamento. Rio de Janeiro: IBGE, 2000.

KLEIN, H. Migração Internacional na história das Américas. In: FAUSTO, Boris. Fazer a América. São Paulo: Edusp, 2000. 
LAZZARI, B. M. Imigração e ideologia: reação do parlamento brasileiro à política de colonização e imigração (1850 - 1875). Porto Alegre: Escola Superior de Teologia de São Lourenço de Brindes. Caxias do Sul: Universidade de Caxias do Sul, 1980.

LIMA, S. C. S. Os filhos do império celeste: a imigração chinesa e sua incorporação à nacionalidade brasileira. Disponível em: <http://redememoria.bn.br/2012/01/ os-filhos-do-imperio-celeste-a-imigracao-chinesa-e-sua-incorporacao-a-nacionalidade-brasileira/>. Acesso em: 14 fev. 2013.

MARTINS, J. S. A imigração e a crise do Brasil agrário. São Paulo: Pioneira, 1973.

PASSOS SUBRINHO, J. M. Reordenamento do trabalho: trabalho escravo e trabalho livre no Nordeste açucareiro: Sergipe 1850-1930. Aracaju: FUNCAJU, 2000.

SAKURAI, C. Imigração japonesa para o Brasil: Um exemplo de imigração tutelada. In: FAUSTO, Boris. Fazer a América. São Paulo: Edusp, 2000.
SILVA, S. A. Bolivianos em São Paulo: entre o sonho e a realidade. Revista Estudos Avançados, São Paulo, n.57, p.157-170, 2006. Disponível em: <http://www.scielo. br/scielo.php?pid=0103-401420060002\&script $=$ sci_ issuetoc>. Acesso em: 23 fev. 2012.

SILVA, S. A. Faces da Latinidade Hispano-Americano em São Paulo. Textos NEPO, Campinas, n.55, p.9-61, 2008.

SILVA, M. A. Guanxi nos trópicos: um estudo sobre a diáspora chinesa em Pernambuco. 2008. 189f. Dissertação (Mestrado em Antropologia) - Departamento de Antropologia, Universidade Federal de Pernambuco, Recife.

TRUZZI, O. Patrícios sírios e libaneses em São Paulo. São Paulo: UNESP, 2009.

VÉRAS, D. B. As diásporas chinesas e o Brasil: a comunidade sino-brasileira em São Paulo. 2008. 280 f. Tese (Doutorado) - Ciências Sociais, Pontifícia Universidade Católica de São Paulo, 2008. 